\title{
Effect of Dust Accumulation on the Performance of Photovoltaic Panels in Desert Countries: A Case Study for Madinah, Saudi Arabia
}

\author{
M. Benghanem ${ }^{1}$, A. Almohammedi ${ }^{2}$, M. Taukeer Khan ${ }^{3}$, A. A. Al-Mashraqi ${ }^{4}$ \\ 1,2,3,4 Physics Department, Faculty of Science, Islamic University, Madinah, Saudi Arabia \\ ${ }^{1}$ International Centre of Theoretical Physics, ICTP, Strada Costiera, 1134014 Trieste, Italy
}

\section{Article Info}

Article history:

Received Apr 21, 2018

Revised Jul 18, 2018

Accepted Aug 2, 2018

\section{Keyword:}

Dust effects

Performance of PV modules

Photovoltaic power losses

\begin{abstract}
The present research shows the effect of dust accumulation on the surface of photovoltaic (PV) modules, which cause losses in their output power. We got $28 \%$ of losses in output power at Madinah city during 60 days of dust accumulation. Two ways were used to study the effect of dust on the PV modules of type monocrystalline silicon: the quantitative and the qualitative approaches respectively. A model based on dust density is used to determine the losses of output PV power. We propose to add an important parameter noted dust accumulation coefficient $\left(\% / \mathrm{mg} \mathrm{cm}^{-2}\right)$, in data sheet of PV modules manufacturer. In addition, an intelligent cleaning system is proposed, using the notion of dust density, to start cleaning when an admissible value of power losses is reached. This process allows minimizing the effect of dust.
\end{abstract}

Copyright (C) 2018 Institute of Advanced Engineering and Science. All rights reserved.

Corresponding Author:

Mohamed Benghanem,

Physics Department, Faculty of Science,

Islamic University in Madinah, Saudi Arabia.

Email: benghanem_mohamed@yahoo.fr

\section{INTRODUCTION}

In renewable energy sources, solar energy is the most used in many applications and photovoltaic system is the principal element for investigation. In fact, many researches focus on the design and economic study for the use of photovoltaic (PV) system [1], the use of maximum power point tracker (MPPT) to improve the efficiency of a PV system [2,3] and also, the use of hybrid system to improve the performance of a PV system [4]. All of these researches are carried out to improve the efficiency of solar cells. In contrast, there are factors that affect the efficiency of solar cells such as high temperature and the accumulation of dust on solar panels, especially in desert regions.

Saudi Arabia is a desert area with conditions of high temperature, drought and frequent sand storms. The region of Madinah is arid and semi-arid region with frequent sand whirlwinds. In this extreme environment, the accumulation of dust and high ambient temperature are a natural process characterized by this environment [5]. Madinah area is characterized by a big potential of solar energy and many applications of PV systems can be done [6]. The ambient temperature is between $40{ }^{\circ} \mathrm{C}$ and $50{ }^{\circ} \mathrm{C}$ during the summer months and sometimes, is over $50^{\circ} \mathrm{C}$. There is low relative humidity and moderate wind speed. The problem encountered is the effect of the environmental parameters, which are high temperature and dust accumulation on the surface of PV panels. These two parameters reduce considerably the efficiency of solar panels. For these reasons, we expect that it is necessary to analysis the impact of dust accumulation on the output power of PV modules and its efficiency. Related to the present work, dust would also refer to the dust storms, which are very often present in Saudi Arabia and particularly in Madinah region. The impairment of the efficiency 
of the solar panels is considered as the most important research problem since it is related to the lower PV power output.

To analyze the effect of dust on solar panel's efficiency, it requires a focus on the blocking factor transmission of sunlight. Due to the thick layer of dust accumulated on the surface of PV panels, the performance of the PV panels is affected. Many scientific works have studied the phenomenon of dust accumulation in solar PV installations. The dust accumulation on the surface of the PV panels decreases the irradiance transmittance during the day by an average between $0 \%$ and $8 \%$ after an exposure period of several months [7]. These losses could reach $15 \%$ in dry areas [8]. A significant degradation in the efficiency of PV modules is observed for dust accumulation due to the sand up to $1 \mathrm{~g} / \mathrm{m}^{2}$, a linear relation has been proposed to correlate the degradation in efficiency to the amount of dust accumulated on the module surface [9]. Different studies have been investigated on the impact of dust on the efficiencies of PV panels. Dust accumulation degrades more critically the efficiency of amorphous and monocrystalline silicon PVs than the panel's temperature or relative humidity [10]. Dust accumulation during dry periods of more than 60 days can reduce production of PV systems up to 15\% [11]. Another study has investigated the effect of dust on the degradation of PV modules deployed in a temperate climate region. The authors state that the total cost of production losses of 13 polycrystalline silicone PV modules caused by dust (US\$ 5.47) is lower than total cleaning cost (US\$ 78). Therefore, no cleaning procedure is recommended for the grid-connected PV system simulated in the case study [12]. A recent work states that the irradiance transmittance is affected by dust accumulation; it was found that the relative transmittance loss was 55\% after 4 months of dust accumulation [13]. In the tropical climate of Thailand, $11 \%$ reduction in irradiance transmittance for a period of 30 days has been found [14]. A new correlation has been found to help photovoltaic system designer to predict the amount of beam solar radiation that would reach the surface of the modules as a function of sand dust particles size and amount accumulated on the surface when they are used in dusty environments [15]. A wide range of results shows that panels with larger tilt angles results in less dust accumulating on panels giving lower transmittance drop. However, small particles still affect solar module efficiency significantly than bigger ones. Abundance in dust accumulation leads to the solar cells deterioration in quality and fill factor. Also, the performances of PV and thermal panels have been measured during several months of outdoor conditions in Saudi Arabia [16]. For the PV module, the average degradation rate of the efficiency was 7\% per month. An experimental study of the impact of accumulation of dust on the area of PV panels has also been done [17]. Different types of dust with different physical properties were used in this study by using a solar simulator as irradiance source. The authors stated that the results depend on several parameters as the main dust material, the density of dust and the size of dust particles. A computerized microscope system has been presented for analyzing the physics of dust particles [18]. This equipment allows researchers to determine the particle size of dust and the percentage of surface covered by dust. Many cases are shown for the use of such measurement system for the study of PV thermal panels. To study the effect of air dust concentration and wind velocity, wind tunnel experiments have been used [19]. Another new experimental work [20] has investigated to study the impact of dust accumulation on solar module in desert environment. The average degradation rate of the efficiencies of the panels are; $6.24 \%, 11.8 \%$ and $18.74 \%$ determined during the periods of one day, seven days and 30 days. In this work the authors have used a solar simulator as light source.

An experimental work has been investigated to study the effect of dust on the transparent cover of solar collectors [21]. This work shows the results of the influence of dust on the transmittance of a glass cover under arid climatic conditions. A new work about the effects of various factors on solar panels power and efficiency has been done [22]. The authors studied the factors affecting dust accumulation and their effects on the transmission coefficient of glass for solar applications. Recently, a work showed that in a 70 days test period, up to $22 \%$ transmission coefficient loss, is caused by the accumulation of dust on the surface [23]. The transmission coefficient loss has been reduced to $0.5 \%$ by using Nano coating deposited on glass samples to create self-cleaning property. In another new work [24], the results indicate that after 70 days without raining, $6.0986(\mathrm{~g} / \mathrm{m} \mathrm{2})$ dust was accumulated on the surface, which caused $21.47(\%)$ reduction in the power output.

In our work we have considered real conditions by studying the effect of dust on the performance of solar panels. We present measurements of different parameters of solar panel and the output power losses produced by the accumulation of dust. The experiment has been carried out at Madinah city (latitude $25.4^{\circ} \mathrm{N}$, longitude $4.5^{\circ} \mathrm{W}$, altitude $60 \mathrm{~m}$, Saudi Arabia). Our aim is to search an experimental setup to avoid and to minimize the effect of dust accumulation on output power and efficiency of solar cells. We also propose an intelligent cleaning system using the notion of dust density to start cleaning when we reached the admissible value of power losses. Also, we propose an important parameter which we have called dust accumulation coefficient $\left(\% / \mathrm{mg} . \mathrm{cm}^{-2}\right)$, which should be given in data sheet of $\mathrm{PV}$ panel manufacturer. 
For this, we present in next section the methodology, by presenting the experimental measurements and showing the effect of dust on IV characterization and efficiency of solar panels. The third section is a discussion about different results obtained and about cleaning process, which is proposed to minimize the dust effect. The conclusion is given in the last section.

\section{METHODOLOGY}

The aim of this paper is to calculate power losses due to dust accumulation on the area of PV panels which have been already calibrated using pyranometer Kipp and Zonen as reference (Type:CMP21). One PV panel has been cleaned daily and the other has not been cleaned throughout the experiment (60 days). The test of the two solar panels used has been done as follows below.

\subsection{Experimental Measurements of Dust Effect}

In the introduction, the effect of dust on the performance of solar panels was highlighted. We have used the cleaning system manually for cleaning the solar modules as shown in the experimental scheme of Figureure. The two panels are oriented south with a tilt equal to the latitude of Madinah city.

We have registered the current-voltage characteristic of two PV panels, one with cleaning system (CLS) every day and the other was kept in outdoors conditions. For this, we have used the following instruments:

1 PVPM 2540C (PV-Engineering (Pve) GmbH, PVPM 2540C, Germany). The PVPM2540C is a portable measuring system with local battery supply and battery charger in durable aluminum housing. This equipment is constituted by a local PC with high- LCD display and thus its function is independent of other devices. However, we can connect an external computer to this device for data transfer and analyze the collected values via a standard USB interface. The PVPM is accessible from the front panel keys and an on-screen menu. A program describing different functions allows the user to familiarize easily with this device.

2 Solar Radiation Sensor (PV-Engineering (Pve) GmbH, SOZ-03, Germany). The SOZ-03 is a calibrated irradiance reference sensor with Monocrystallin cell technology. The length of the lead is $10 \mathrm{~m}$.

3 Temperature surface sensor (PV-Engineering (Pve) GmbH, Pt100, Germany). For the measurement of the back surface temperature of the solar panel under test, we use the temperature surface sensor PT100, stainless steel housing, temperature range is between $-30^{\circ} \mathrm{C}$ to $+105^{\circ} \mathrm{C}$, accuracy respecting to DIN $1 / 3$ B. cable $10 \mathrm{~m}$.

4 Thermocouple of type $\mathrm{K}$ for measuring the ambient temperature.

5 Digital Multimeter (PeakTech, 3695, Germany) using thermocouple for collecting the ambient temperature.

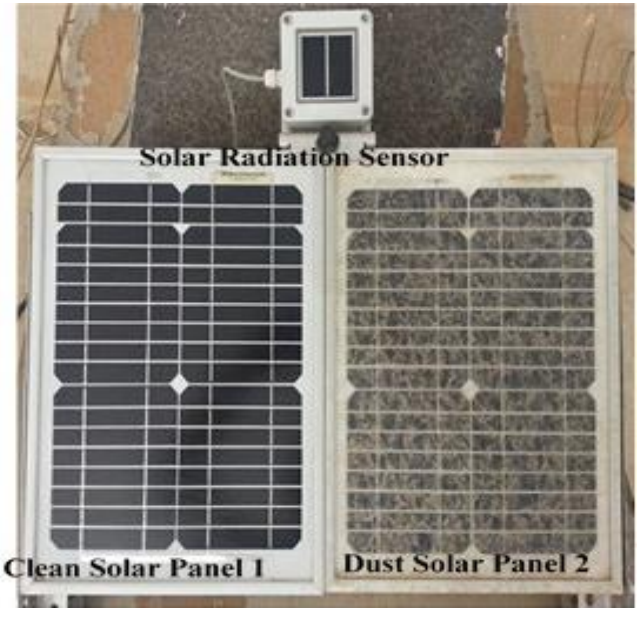

(a)

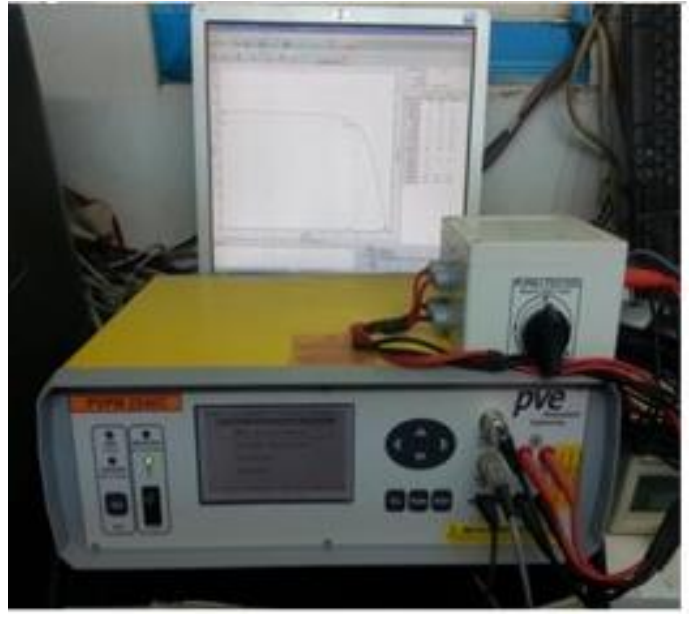

(b)

Figure 1. Experimental Setup of Dust Accumulation Effect

(a) Cleaned Solar Panel 1 and Dusty Solar Panel 2; (b) PVPM 2540C 
The IV characteristics of the two solar panels used are presented in Figure 2. Also, Table1 shows the parameters of the two solar panels before dust.

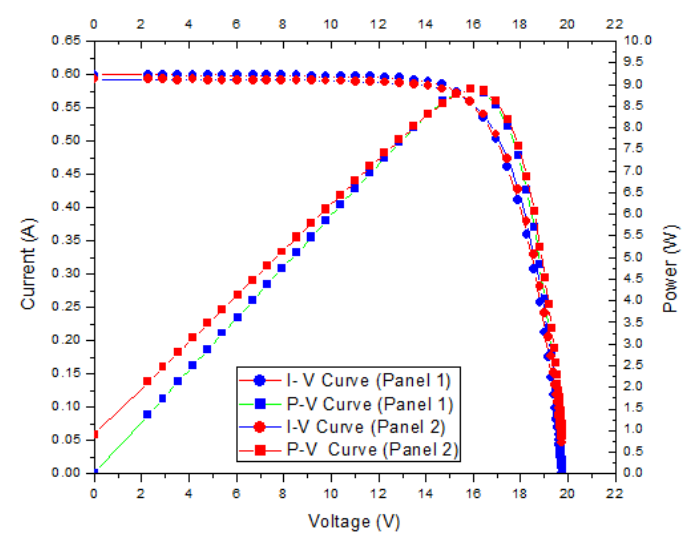

Figure 2. Current-Voltage and Power-Voltage Characteristic for Solar Panel 1 (clean) and Panel 2 (Dusty)

\subsection{Effect of dust on I-V Characterization and Efficiency on Solar Panels}

The impairment of the efficiency of the solar panels can be considered as the most important problems experienced by users of PV systems, and thus lower power output. Saudi Arabia is a desert area with conditions of high temperature, drought and frequent dust storms. In this extreme environment, the accumulation of dust is a natural process characterized by this environment. The output of the energy decreases day by day because the increasing accumulation of dust and neglect of cleanliness.

In this part, we present the impact of natural dust accumulation on the PV module and the way to avoid this problem.

\subsubsection{Effect of Dust on I-V Characterization}

The variation in accumulation of the dust allows different transmittance of light into the solar cell, thus leading to small random surfaces on the solar panel with partial shading from incident solar irradiation. The major problem encountered in Saudi Arabia in PV applications, is the environment conditions, which are characterized by high temperatures and frequent dust storms. For this purpose, we have concentrated on the effect of dust density on the I-V characterization of solar modules. We present in this section a fundamental concept of why and how dust affects solar panel performance.

To show the effect of dust accumulation, we study the effect of different concentrations of dust on the solar panels, which its characteristics are presented in Table 1.

Table 1. The parameters of Two Solar Panels Used Before Dust Accumulation

\begin{tabular}{ccc}
\hline Parameters & Solar panel 1 & Solar panel 2 \\
\hline Size $\left(\mathrm{cm}^{2}\right)$ & 684 & 684 \\
Solar irradiation $\left(\mathrm{W} / \mathrm{m}^{2}\right)$ & 832 & 821 \\
Cell Temperature $\left({ }^{\circ} \mathrm{C}\right)$ & 50 & 50 \\
Ambient Temperature $\left({ }^{\circ} \mathrm{C}\right)$ & 39 & 39 \\
Isc (A) & 0.60 & 0.59 \\
Voc (V) & 19.8 & 19.8 \\
Impp (A) & 0.56 & 0.55 \\
Vmpp (V) & 15.8 & 15.9 \\
Fill factor $(\%)$ & 64.1 & 64.2 \\
Efficiency $(\%)$ & 11.6 & 11.5 \\
\hline
\end{tabular}

The dust accumulation on the solar panel surface produces spots with different density of dust particles as presented in Figure 3. 


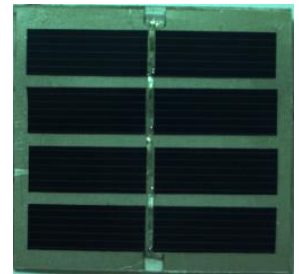

Clean

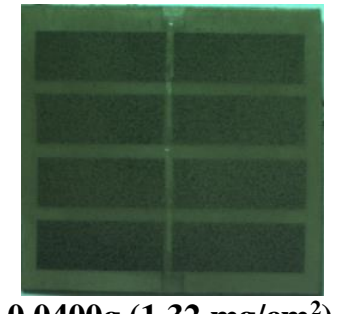

$0.0400 \mathrm{~g}\left(1.32 \mathrm{mg} / \mathrm{cm}^{2}\right)$
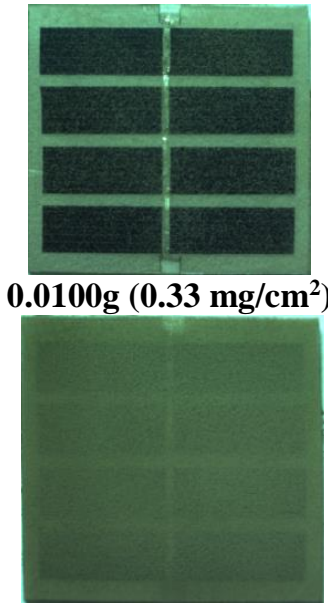

$0.0800 \mathrm{~g}\left(2.65 \mathrm{mg} / \mathrm{cm}^{2}\right)$
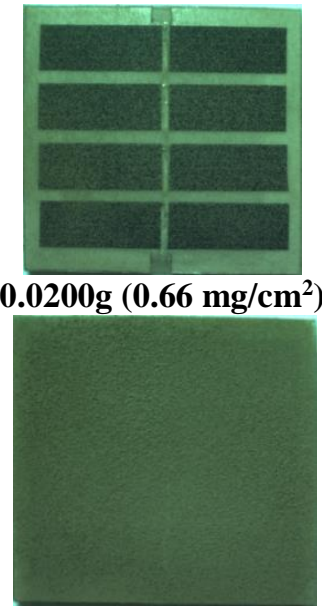

$0.1600 \mathrm{~g}\left(5.29 \mathrm{mg} / \mathrm{cm}^{2}\right)$

(a) Different Dust Density

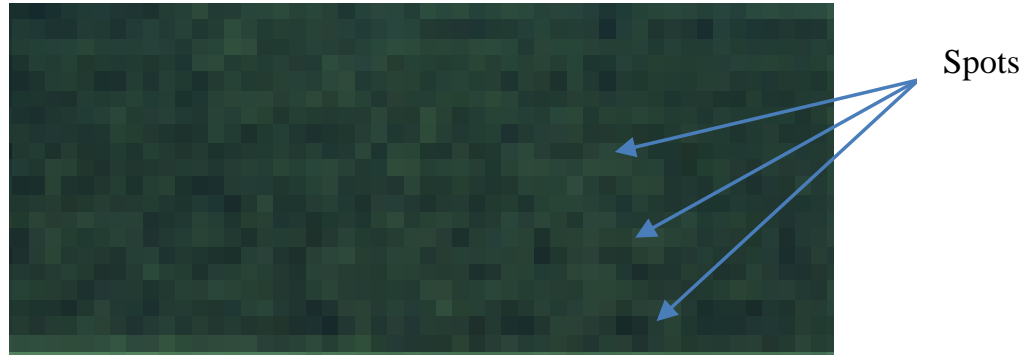

(b) Spots Variation for a Small Area of the Solar Cell

Figure 3. Dust Accumulation with Different Dust Surface Density for $30 \mathrm{~cm}^{2}$ of Solar Panel Area

These spots vary in shape, location and dust density. So, the dust has a direct effect by minimizing the performance of PV cells. So, dust accumulation allows the reduction of the open-circuit voltage and the shortcircuit current, as shown in Figure.4. For this measurement, we have used Source Meter (Keithley Instruments, 2420, USA) at solar irradiation of $860 \mathrm{~W} / \mathrm{m}^{2}$ and cell temperature of $40^{\circ} \mathrm{C}$.

Figure 5 shows the effect of dust density on output power of solar panels in function of voltage at irradiation of $860 \mathrm{~W} / \mathrm{m} 2$. We note that the output power is reduced with increasing dust density.

The representation of losses that occurs at the open-circuit voltage, the short-circuit current and output power, are represented in Figure 6.

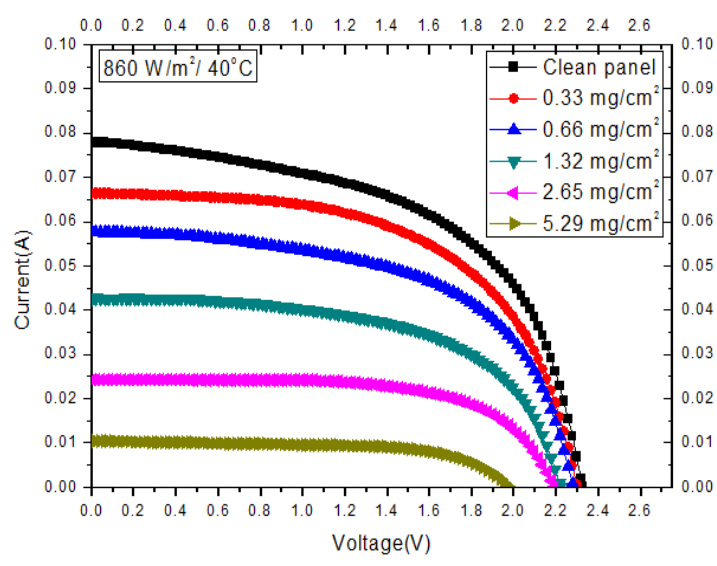

Figure 4. Effect of Dust Accumulation Density on I-

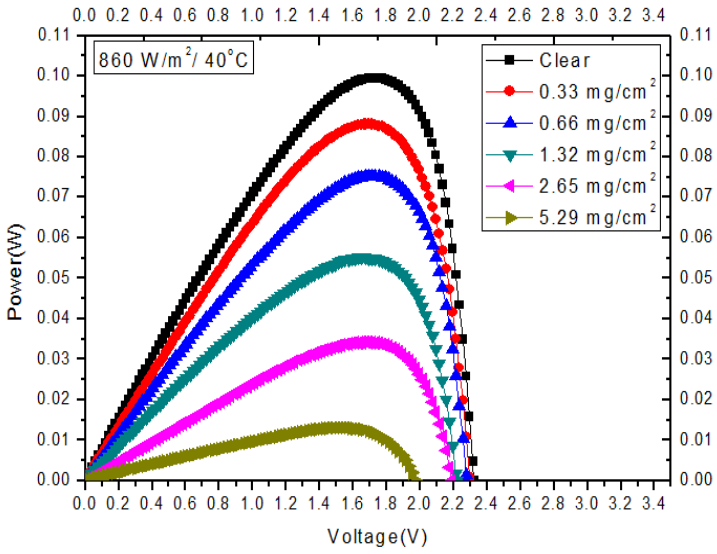

Figure 5. Effect of Dust Accumulation Density on 


\section{Characteristic Output Power of Solar Panel}

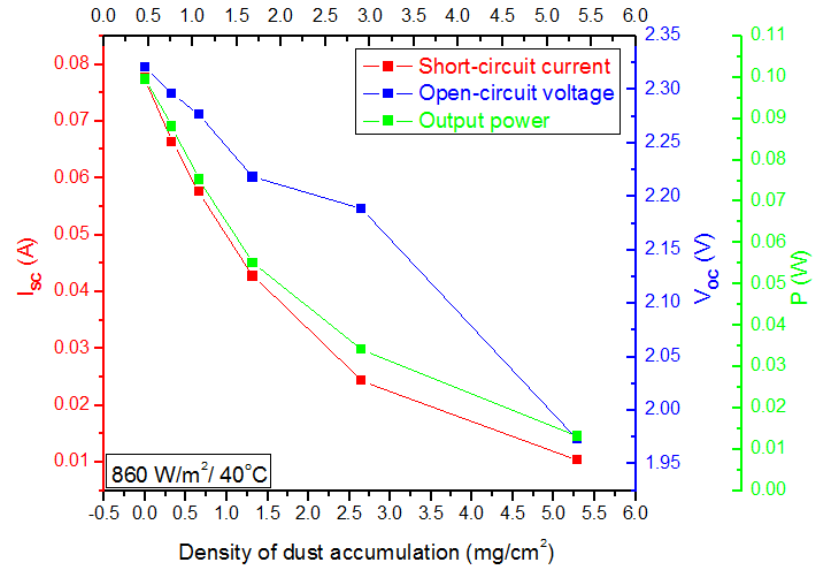

Figure 6. Effect of Dust Accumulation Density on Short Circuit Current $\left(I_{S C}\right)$, Open Circuit Voltage $\left(V_{O C}\right)$ and Output Power (P) of Solar Panels

In the curve above, increasing dust accumulation leads to a reduction in the open-circuit voltage (Voc), the short-circuit current (Isc) and in the output power (PM). Therefore, to highlight the losses as a result of rise in dust, we have calculated the percentage of loss for Voc, Isc and PM. The loss of the Voc is approximately $15 \%$ if dust accumulation rises up to $5.29 \mathrm{mg} / \mathrm{cm} 2$. Also, this loss of the open-circuit voltage could be neglected, by comparison with the loss of the short-circuit current; which is approximately $86 \%$.

Table 2 represents the losses of output power with dust accumulation for the mini solar panel used. The variation of current $(\Delta \mathrm{IM})$ corresponding to the variation of dust accumulation during $5.29 \mathrm{mg} / \mathrm{cm} 2 \mathrm{is}$ $0.0488 \mathrm{~A}$; thus the rate of decrease is $85 \%$. Also, the variation of voltage $(\Delta \mathrm{VM})$ is $0.2014 \mathrm{~V}$ corresponding to the rate of decrease of $12 \%$.

The maximum variation for power output is $0.0864 \mathrm{~W}$, which correspond to the rate of decrease of $87 \%$. This increase in accumulation of dust will lead to the loss of resulting power. This means if a clean solar panel of type monocrystalline silicon, :will produce 100 watt, a dust accumulation of $5.29 \mathrm{mg} / \mathrm{cm} 2$ density leads to that type of panel produces only 13 watts during a long periods of time.

Table.2 The Parameters of $I_{M}, V_{M}$ and $P_{M}$ vs. Difference of Dust Accumulation

\begin{tabular}{ccccccc}
\hline $\begin{array}{c}\text { Dust accumulation } \\
\text { density }\left(\mathrm{mg} / \mathrm{cm}^{2}\right)\end{array}$ & $I_{S C}(\mathrm{~A})$ & $V_{O C}(\mathrm{~V})$ & $I_{M}(\mathrm{~A})$ & $V_{M}(\mathrm{~V})$ & $P_{M}(\mathrm{~W})$ & Efficiency $(\%)$ \\
\hline 0 & 0.0776 & 2.321 & 0.05743 & 1.7323 & 0.0995 & 13.8791 \\
0.33 & 0.0663 & 2.296 & 0.05206 & 1.69199 & 0.0881 & 12.2886 \\
0.66 & 0.0576 & 2.277 & 0.04400 & 1.7121 & 0.0753 & 10.5095 \\
1.32 & 0.0427 & 2.218 & 0.03337 & 1.65181 & 0.0551 & 7.6898 \\
2.65 & 0.0243 & 2.188 & 0.02046 & 1.67202 & 0.0342 & 4.7725 \\
5.29 & 0.0104 & 1.973 & 0.00858 & 1.5309 & 0.0131 & 1.8324 \\
\hline
\end{tabular}

\subsubsection{Effect of Dust on Efficiency of PV Modules}

To analysis the impact of dust on solar panel's performance, it requires a focus on the blocking factor transmission of sunlight. The presence of a thick layer of dust accumulated on the area of PV panels, affects the performance of PV panels. For that, the photo-current is directly related to the number of photons absorbed thus it is proportional to the solar irradiation [25]. Also, the PV power output is proportional to the solar irradiation. In the previous Figure 4, the decrease in the voltage for a given dust accumulation rise is proportionately lower than the decrease in current. Consequently, this increase in accumulation of dust will lead to the loss of resulting power. So, the total effect on power tends to be the same effect to that on current. As shown in Figure. 7 , if the dust accumulation rises up to $5.29 \mathrm{mg} / \mathrm{cm} 2$, we get $87 \%$ of efficiency loss.

The efficiency of the solar panel [6] is reduced according to the Equation (1). Also, in addition to the effect of temperature, dust accumulation plays major factor in determining the solar panel efficiency.

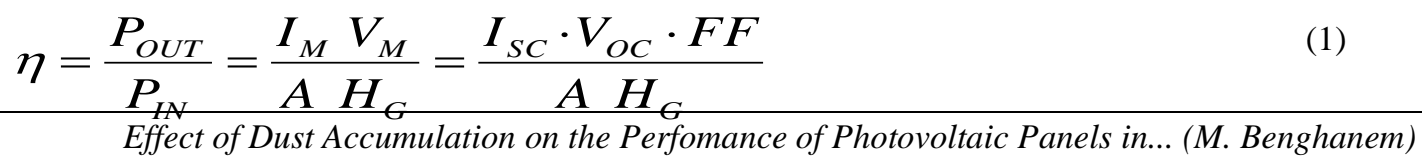


Where $I_{M}$ and $V_{M}$ represent the maximum current and voltage given by a solar cell, $A$ is the area of solar cell $\left(\mathrm{m}^{2}\right)$ and $H_{G}$ is the intensity of incident solar irradiation $\left(\mathrm{W} / \mathrm{m}^{2}\right)$. FF represents the fill factor or of solar panels.

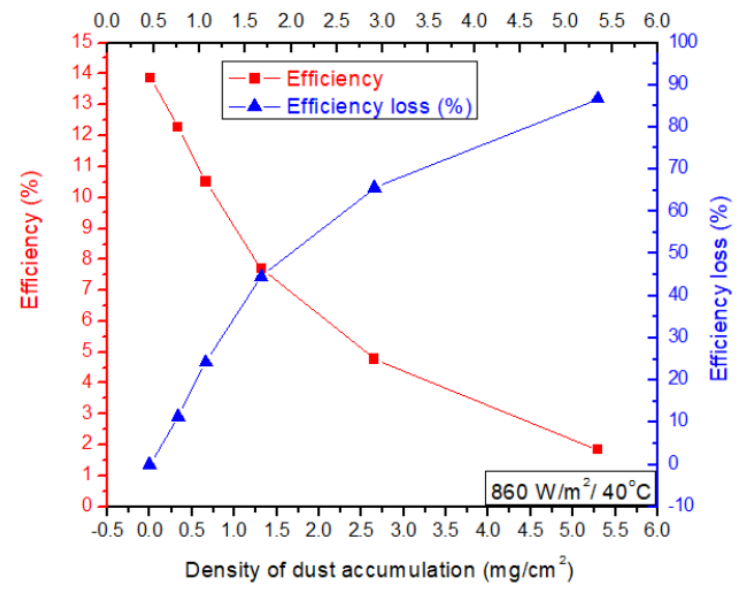

Figure 7. Evolution of Efficiency and Efficiency Loss vs Dust Density

\section{DISCUSSION}

Dust accumulation limits the light transmittance or lead to different transmittance of light inside the solar cell. So, it significantly affects the performance of PV module. Due the light-generated current is directly related to the number of photons absorbed thus it is proportional to the solar irradiation. Also, the PV power output is proportional to the solar irradiation. The calculation of energy losses due to the presence of dust has to be estimated in a different way for stand-alone PV system and solar tracking system.

For our experimental study, we have used two approaches to study the phenomenon of dust on the solar panels effect in Madinah site. The study period for measurement was four months of dust accumulation (May-August 2017).

\subsection{The Quantitative Approach}

For measuring the accumulation of dust during a certain period of time, we have used a solar panel for the specification at STC conditions. In our experimental work, we have used 60 days for natural accumulation of dust to calculate the resulting loss of output power. In Table 3, the variation of current $\left(\Delta I_{M}\right)$ corresponding to the variation of dust accumulation during 60 days is $0.1541 \mathrm{~A}$; thus the rate of decrease is $26 \%$. Also, the variation of voltage $\left(\Delta V_{M}\right)$ is $0.7182 \mathrm{~V}$ corresponding to the rate of decrease of $4 \%$. The maximum variation for power output is $2.7320 \mathrm{~W}$, which correspond to the rate of decrease of $28 \%$.

Table 3. The Parameters of $I_{S C}, V_{O C}, I_{M}, V_{M}$ and $P$ vs. Days of Dust Accumulation

\begin{tabular}{cccccc}
\hline $\begin{array}{c}\text { Dust accumulation } \\
\text { (Days) }\end{array}$ & $I_{S C}(\mathrm{~A})$ & $V_{O C}(\mathrm{~V})$ & $I_{M}(\mathrm{~A})$ & $V_{M}(\mathrm{~V})$ & $P(\mathrm{~W})$ \\
\hline 0 & 0.63062 & 20.01047 & 0.59176 & 16.1050 & 9.46624 \\
6 & 0.62353 & 20.0026 & 0.57812 & 16.1050 & 9.31066 \\
12 & 0.61871 & 19.84221 & 0.56858 & 15.8836 & 8.86048 \\
23 & 0.6099 & 19.76873 & 0.56312 & 15.7393 & 8.58159 \\
31 & 0.59571 & 19.36317 & 0.55903 & 15.2589 & 8.53024 \\
40 & 0.58371 & 19.09756 & 0.52767 & 15.2589 & 8.2128 \\
42 & 0.54021 & 19.10149 & 0.49767 & 15.3573 & 7.64283 \\
60 & 0.45948 & 18.92639 & 0.43766 & 15.3868 & 6.73428 \\
\hline
\end{tabular}

The decrease in the voltage for a given dust accumulation rise is proportionately lower than the decrease in current. Consequently, this increase in accumulation of dust will lead to the loss of resulting power. So, the overall effect on power tends to be similar to that on current. On another hand, the variation of 
short circuit current $\left(\Delta I_{S C}\right)$ corresponding to the variation of dust accumulation during 60 days is $0.1711 \mathrm{~A}$; thus the rate of decrease is $27 \%$. Also, the variation of voltage $\left(\Delta V_{O C}\right)$ is $1.084 \mathrm{~V}$ corresponding to the rate of decrease of $5 \%$. So, we can say that the effect on losses of $V_{O C}$ and $I_{S C}$ tends to be similar to that on $V_{M}$ and $I_{M}$, respectively. This increase in accumulation of dust will lead to the decrease of efficiency according of the light-generated current $\left(I_{P V}\right)$ which it's depending on the solar irradiation as mentioned in the relation (1).

The use of experimental results for the limited number of days is not enough to conclude about the resulting losses of output power. Therefore, we need a large measurement over the year and to repeat these measurements for each two months in order to get more accuracy and then better results. This helps us to build a database of the behavior of dust on solar cells during the year in Madinah site.

\subsection{The Qualitative Approach}

In this approach, we have used the notion of dust density, which allows us to determine the losses of output PV power for a small cell reference. The idea is to establish a relation between natural dust accumulation during days in term of dust density and output PV power. Fortunately, we have measured the density of dust accumulation and the PV output power at the same measurement conditions $\left(860 \mathrm{~W} / \mathrm{m}^{-2}\right.$, $40^{\circ} \mathrm{C}$ ). For this, we have chosen the loss of output power of cell reference as a link to deduct the density of dust accumulation for a tested solar cell.

The representation of dust accumulation density vs. losses of output power allow us to measure the density of dust accumulation for the studied solar panel, knowing the losses of output power as it is mentioned in Figure 7. By fitting the experimental data, we find an empirical equation that gives the density of dust accumulation in function of losses of output power. We propose to use this equation to calibrate the solar panel used as reference. In fact, the idea is to calculate the density of dust accumulated on the studied solar panel knowing the losses of output power of solar panel calibrated.

At the first, we have used the polynomial fitting which gave us the correlation coefficient of 0.984 and the regression model is:

$$
D=7.35 \times 10^{-4} L^{2}-65.9 \times 10^{-4} L+0.18
$$

So, in order to improve the adjustment coefficient, we have tested the exponential model which gave us a better coefficient of 0.998 . So, the empirical equation chosen is given as follow:

$$
D=0.47 e^{\left(\frac{L}{34.93}\right)}-0.37
$$

Where $L$ is the losses of output power (\%) and $D$ is the dust accumulation density $\left(\mathrm{mg} / \mathrm{cm}^{2}\right)$.

For dust accumulation effect, it is necessary to highlight the energy losses produced by dust in desert areas, like Madinah site. In fact, in such location, losses reach high values and so affect the performance of solar modules due to the decrease of its efficiency and then the efficiency of photovoltaic systems became lower. The expected losses caused by the accumulation of dust, which helps in predicting annual energy yield in a specific area to know whether cleaning process technology should be invested in or not. We suggest an important factor called sand dust accumulation coefficient $\left(-16.45 \% / \mathrm{mg}^{-\mathrm{cm}^{-2}}\right)$, which should be added in data sheet of PV panels manufacturer. In fact, in data sheet of PV panels there is a coefficient of temperatures $\left(\% /{ }^{\circ} \mathrm{C}\right)$ which gives the losses of output power of PV panel for $1{ }^{\circ} \mathrm{C}$ increase in temperature. So, it is much better, if the PV panels should be installed in locations with a big concentration of dust, to add in the data sheet the new coefficient which called "Sand Dust accumulation coefficient" $\left(\% / \mathrm{mg}^{\mathrm{cm}} \mathrm{cm}^{-2}\right)$.

\subsection{Cleaning Process}

As mentioned previously, dust plays a significant role in decreasing the PV power output in desert areas. Thus, achieving good energy collection efficiencies requires constant cleaning of the PV modules. Usually, for the large area of solar panels, water is used in the cleaning process; but in arid regions, the lack of water requires for alternative cleaning processes that can minimize the amount of water required. Sustainable cleaning methods are particularly important in large scale utilization of solar panels. There is a variety of methods that can be used to clean the PV modules. Manual cleaning is the most obvious, but it comes at the cost of labors and it is the most time consuming method. An alternative that is being extensively investigated relies on the use of self-cleaning coatings that minimize dust accumulation. Studies show that super-hydrophobic surfaces exhibit self-cleaning properties [25-28]. In our experimental work, we have used the manual cleaning method because the area of the solar panel used is small one. For a large PV area, we 
propose an intelligent cleaning system (Figure.8) using the notion of dust density to start cleaning when we reached the admissible value of power losses using the model Losses-Power density (3).This process allows minimizing the effect of dust.

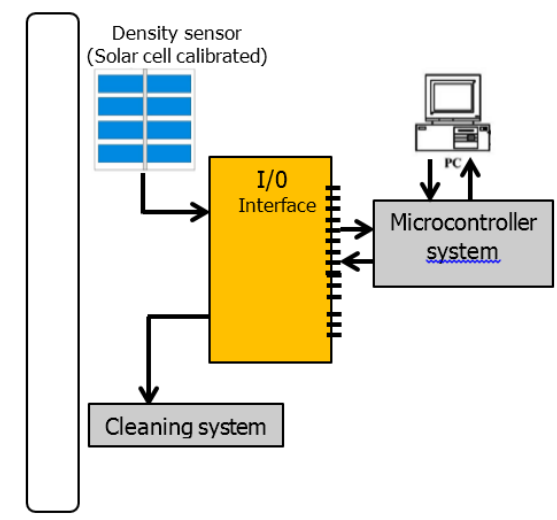

Figure.8. Intelligent cleaning system based on dust density measurement

So, a daily cleaning of the PV panels would be important but this will increase the maintenance costs. Therefore, we suggest also using a different alternative ways for manual cleaning, to be economical and give high efficiency. Often, we suggest use the coating methods [26]. Variables such as the composition and manufacturing process of the coating, the type of dust, weather conditions (e.g. humidity and temperature) and their interactions should be studied thoroughly to be able to develop a coating having selfcleaning properties.

\section{CONCLUSION}

The effect of the temperature and dust accumulation on the PV panel surface was analyzed at Madinah site, which is characterized by a desert environment. We studied the impact of dust on IV characteristic and efficiency of solar panels.

Although our data are limited in time, we managed to describe qualitatively the dust accumulation dependence on Madinah environment. The objective is to find the effect of dust on the performance of photovoltaic panels. So, this work has highlighted the impact of dust on the I-V and P-V characteristics of PV panels during two months of dust accumulation on the solar system. We conclude that all solar cell parameters $\left(P_{M}, I_{M}, I_{S C}, R_{S}, R_{S h}\right.$ and $\left.F F\right)$ are affected by the dust deposits on the PV panels surface. The output power $P_{M}$ loss is about $28 \%$, if dust accumulation rises up 60 days. Also, the short circuit current $I_{S C}$ loss can reaches the value of $27 \%$. However, the open circuit voltage $V_{O C}$ loss is around $5 \%$ during the studied period. In fact, there would have been quite a large loss of module efficiency if solar panels were exposed to more dusty areas in KSA in general. Although rain causes the cleaning of module and minimize the effect of dust on solar cells, it cannot be relied on it for cleaning because there are little rains at Madinah site during the year. Thus, the PV modules require regular cleaning to minimize the effect of dust and then minimizing the efficiency loss.

\section{ACKNOWLEDGMENTS:}

This work was supported by the Dean of Scientific Research of Islamic University, Madinah, Kingdom of Saudi Arabia, under Project number: 39/65. All collaboration works are gratefully acknowledged.

\section{REFERENCES}

[1] H. Shahinzadeh et al., "Design and Economic Study for Use the Photovoltaic Systems for Electricity Supply in Isfahan Museum Park," International Journal of Power Electronics and Drive System (IJPEDS), 3 (1), 83-94 (2013). 
[2] A. Hassani et al., "A New High Speed and Accurate FPGA-based Maximum Power Point Tracking Method for Photovoltaic Systems," International Journal of Power Electronics and Drive System (IJPEDS), 8 (1), 1335-1344 (2017).

[3] H. Abouobaida and E. B. Said, "Practical Performance Evaluation of Maximum Power Point Tracking Algorithms in a Photovoltaic System," International Journal of Power Electronics and Drive System (IJPEDS), 8 (4), 1744-1755 (2017).

[4] A. Lekbir et al., "The Recovery of Energy from a Hybrid System to Improve the Performance of a Photovoltaic Cell," International Journal of Power Electronics and Drive System (IJPEDS), 9 (3), 957-964 (2018).

[5] M. Benghanem et al., "Performance of solar cells using thermoelectric module in hot sites," Renewable Energy. 89, 51-59 (2016).

[6] M. Benghanem et al., " Performances of solar water pumping system using helical pump for a deep well: A case study for Madinah, Saudi Arabia," Energy Conversion and Management, 65, 50-56 (2013).

[7] S. Semaoui et al., "Dust Effect on Optical Transmittance of Photovoltaic Module Glazing in a Desert Region," Energy Procedia. 74, 1347-1357 (2015).

[8] S. Kalogirou et al., "On-site PV characterization and the effect of soiling on their performance," Energy. 51, 439-446 (2013).

[9] Ahmad Y. Al-hasan and Adel A. Ghoneim," A new correlation between photovoltaic panel's efficiency and amount of sand dust accumulated on their surface," International Journal of Sustainable Energy, Vol.24, 4 (2005).

[10] F.A. Touati et al., "Study of the Effects of Dust, Relative Humidity, and Temperature on Solar PV Performance in Doha: Comparison between Monocrystalline and Amorphous PVS," International Journal of Green Energy, 10, 7 (2013).

[11] B. Weber et al., "Performance Reduction of PV Systems by Dust Deposition," Energy Procedia, 57, 99-108 (2014).

[12] J. Tanesab et al., "Dust Effect and its Economic Analysis on PV Modules Deployed in a Temperate Climate Zone," Energy Procedia, 100, 65-68 (2016).

[13] P. Ferrada et al., "Characterization of soiling on PV modules in the Atacama Desert," Energy Procedia, 124, 547-553 (2017).

[14] G. Mastekbayeva and S. Kumar," Effect of dust on the transmittance of low density polyethylene glazing in a tropical climate," Solar Energy, 2, 135-141 (2000).

[15] A.Y. Al-Hasan, "A new correlation for direct beam solar radiation received by photovoltaic panel with sand dust accumulated on its surface," Solar Energy, 63(5), 323-333 (1998)

[16] A.A.M. Said, "Effects of dust accumulation on performances of thermal and photovoltaic flat-plate collectors," Applied Energy, 37(1), 73-84 (1990)

[17] M.S. El-Shobokshy and F.M. Hussein, "Effect of dust with different physical properties on the performance of photovoltaic cells," Solar Energy, 51(6), 505-511 (1993).

[18] S. Biryukov et al., "An optical system for the quantitative study of particulate contamination on solar collector surfaces," Solar Energy, 66(5), 371-378 (1999).

[19] D. Goossens and E.Van Kerschaever, "Aeolian dust deposition on photovoltaic solar cells: the effects of wind velocity and airborne dust concentration on cell performance," Solar Energy, 66(4), 277-289 (1999).

[20] M. Saidan et al., "Experimental study on the effect of dust deposition on solar photovoltaic panels in desert environment," Renewable Energy, 92, 499-505 (2016).

[21] M.M. Rahman et al., "Effects of various parameters on PV-module power and efficiency," Energy Conversion and Management, 103, 348-358 (2015).

[22] Gholami, A., Saboonchi, A., \& Alemrajabi, A. A, "Experimental study of factors affecting dust accumulation and their effects on the transmission coefficient of glass for solar applications, Renewable Energy, 112, 466-473 (2017).

[23] Gholami, A., Alemrajabi, A. A., \& Saboonchi, A, "Experimental study of self-cleaning property of titanium dioxide and nanospray coatings in solar applications," Solar Energy, 157, 559-565 (2017).

[24] Gholami, A., Khazaee, I., Eslami, S., Zandi, M., \& Akrami, E, "Experimental investigation of dust deposition effects on photo-voltaic output performance, " Solar Energy, 159, 346-352 (2018).

[25] Y. Tsuno et al., "Temperature and Irradiance Dependence of the I-V Curves of Various Kinds of Solar Cells," International Photovoltaic Science \& Engineering Conference (PVSEC-15), 422-423 (2005).

[26] I.P. Parkin and R.G. Palgrave, "Self-cleaning coatings," Journal of Materials Chemistry, 15(17), 1689-1695 (2005)

[27] He. Gaofa et al., "Review of Self-Cleaning Method for Solar Cell Array," Procedia Engineering, 16, $640-645(2011)$

[28] Y.B. Park et al., "Self-cleaning effect of highly water-repellent microshell structures for solar cell applications," Journal of Materials Chemistry, 21(3), 633 (2011). 


\section{BIOGRAPHIES OF AUTHORS}
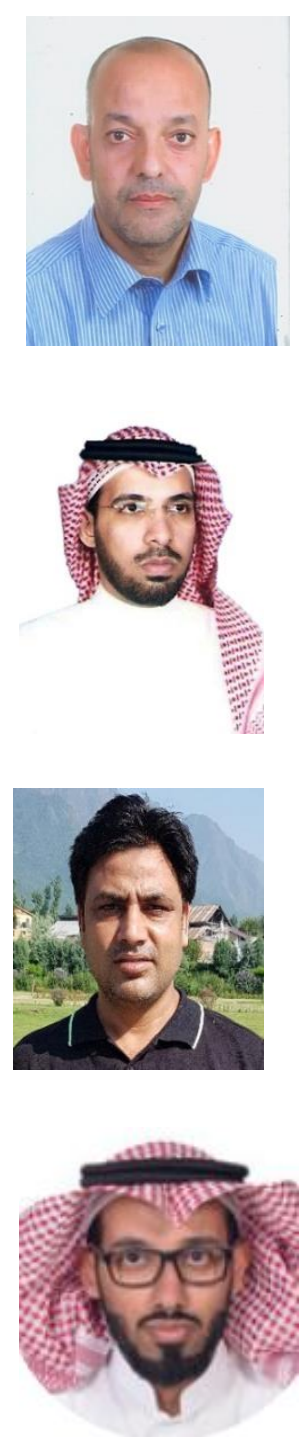

Mohamed Benghanem is Professor at Islamic University, Faculty of Science, Physics Department (since 2017). He was at Taibah University, Faculty of Science, Madinah, Saudi Arabia (2004-2016). He was Regular associate at International Centre of Theoretical Physics, ICTP, Italy since 2004 and now, he is senior associate until August 2018. He obtained his BE, MSc and Ph.D. in Electrical Engineering from Polytechnic School of Algiers, USTHB University, Algiers (Algeria) and University Polytechnic of Madrid-UPM (Spain) respectively. His research interests are solar instrumentations, data acquisition systems, Photovoltaic systems, renewable energy systems and prediction and modeling of solar radiation data.

Abdullah Almohammedi is Dean of the faculty of science at Islamic University of Medinah. His research focus on energy harvesting devices. He did his $\mathrm{Ph}$. D. from University of Leicester, Leicester, UK in 2016. His main research interests are Material Science, Raman Spectroscopy, Fluorescence Spectroscopy, Nanotechnology, Spectroscopic Analysis in Biological materials.

Mohd Taukeer Khan is an Assistant Professor at the Islamic University of Medinah. His research focus is on charge transport mechanism in organic semiconductors based devices. He obtained his $\mathrm{PhD}$ in organic solar cells from the National Physical Laboratory New Delhi, India. He has worked as a postdoctoral Researcher at University of Leeds in the field of organic spintronics. His main research interests are to understand the spin dependent charge transport in organic semiconductors.

Ahmad Abdo Al-Mashraqi obtained his Master's degree in 2016, in Physics, Solar Cells. His research interests are solar instrumentations, renewable energy systems, modeling of solar radiation data, the generation of plasma and applications and design configuration of Plasma jet systems and laser applications. 